\title{
Effects of Human Thymic Epithelial-Conditioned Medium on Mitogen Responsiveness of Human and Mouse Lymphocytes
}

\author{
Robert Oosterom, Louis Kater, and Jonet Oosterom \\ Division Immunopathology, Departments of Internal Medicine and Pathology, \\ University Hospital, $3511 \mathrm{GV}$ Utrecht, The Netherlands
}

Received August 2, 1978

\begin{abstract}
The conditioned media from a variety of human tissue cultures, thymus, HeLa cells, labial epithelium, salivary glands, and fibroblasts, were examined for their effect on the response of human and mouse lymphocytes to mitogens. Conditioned media from thymus epithelial cultures (HTECM), but not from nonthymic epithelial cultures and fibroblasts, increased $\left[{ }^{3} \mathrm{H}\right] \mathrm{TdR}$ incorporation into Con A- and PHA-stimulated thymocytes of man and mouse. No effect was seen on B lymphocytes. Target cells for HTECM were not found in human peripheral blood lymphocytes. In the mouse target cells were found in two thymocyte subpopulations, the cortisone-resistant and cortisone-sensitive, and in the spleen. Lymph node cells contained no target cells.
\end{abstract}

\section{INTRODUCTION}

It is well known that the thymus is essential for T-lymphocyte development ( 1 , 2). Precursor cells migrate from bone marrow to the thymus where development and maturation take place (3). During the maturation process thymocytes migrate from cortical areas, where immature cells reside, to medullary regions where more differentiated cells are located. This maturation process is characterized by changes in surface markers, response to mitogens, and functional properties (4). The mechanism by which this maturation takes place is poorly understood.

A number of thymic humoral factors, which are thought to replace partly the thymus in inducing T-lymphocyte maturation, have been described in recent years (reviews: 5,6 ). The factors are probably produced by thymic epithelial cells. This may imply that thymic humoral factors can be produced in vitro by cultured thymic epithelial cells. Such an in vitro thymus epithelium culture system may also solve the problem of whether humoral factors isolated from thymus tissue are actually from epithelial or lymphocytic origin. Evidence for the secretion of humoral factors by cultured thymic epithelium stems from the observation that supernatants of human thymic epithelium have proved to be capable of inducing E-rosette-forming cells in fractionated bone marrow cells (7). Theta conversion of spleen cells of adult thymectomized mice was obtained when these cells were incubated within a Millipore chamber on human thymic epithelial monolayers (8). With rat thymic epithelial culture supernatant, the response of rat thymocytes to mitogenic and allogeneic stimulation could be increased $(9,10)$.

The present study deals with the effects of a humoral factor produced by cultured human thymic epithelial cells on the mitogen responsiveness of human and mouse lymphocytes, compared with the effects of conditioned media of other human tissue cultures, both fibroblasts and epithelium. In an attempt to identify 
the possible target cell(s) for this factor the effects on thymocytes at various days after cortisone treatment of mice were investigated.

\section{MATERIAL AND METHODS}

Human thymic epithelial cultures and control cultures. Human thymuses were obtained from children undergoing cardiac surgery. Under aseptic conditions the capsular tissue was removed and thymuses were minced in small pieces. Tissue fragments were washed in HEPES (25 mM)-buffered RPMI-1640 medium (HRPMI) (Gibco Biocult Ltd., Scotland) in order to remove most of the thymocytes. Fragments were explanted in Falcon tissue culture flasks together with a few milliliters of culture medium. After 1 or 2 days, when the explants were attached to the flasks, $5 \mathrm{ml}$ fresh medium was added. The culture medium consisted of H-RPMI supplemented with $2 \mathrm{mM}$ L-glutamine, penicillin $(100 \mathrm{U} / \mathrm{ml})$, streptomycin $(100 \mu \mathrm{g} / \mathrm{ml})$, and $20 \%$ heat-inactivated human AB serum. Cultures were kept at $37^{\circ} \mathrm{C}$ and medium was changed twice a week.

Control cultures used were fibroblasts grown from a cervical biopsy, HeLa cells, and epithelial cells grown from labial mucosae and salivary glands obtained from patients undergoing labial biopsy. These epithelial cells were chosen because of their ectodermal origin was like thymus epithelium (11). The cervical biopsy, labial mucosae, and salivary glands were treated in the same way as described for thymus tissue.

Collecting of conditioned media. Conditioned media from the thymic epithelial cultures (HTECM) were collected from the time that thymocytes had disappeared from the cultures, usually at Day 10, until about Day 35. Conditioned media from cultures of labial epithelium (HLECM) and epithelium of salivary glands (HSECM) were collected in the same way. Conditioned media from HeLa cells and fibroblasts (HFCM) were collected from the time that the cells had covered more than $50 \%$ of the tissue culture flask surface until they were subcultured by treatment with $0.05 \%$ trypsin-EDTA solution (Gibco Biocult L.td.)

Media collected from the tissue cultures were centrifuged at $1000 \mathrm{~g}$ for $10 \mathrm{~min}$, filtered through Millipore filters $(0.45 \mu \mathrm{m})$, and stored in small aliquots at $-20^{\circ} \mathrm{C}$.

Mitogen stimulation of human lymphocytes. Thymocytes removed from thymus tissue fragments from young donors were washed with H-RPMI and counted in a hemocytometer, and viability was assessed by 'Trypan blue dye exclusion: cell viability was always greater than $95 \%$. The cell suspension was adjusted to $10 \times 10^{6} / \mathrm{ml}$ in RPMI-1640 with bicarbonate, antibiotics, and $20 \% \mathrm{AB}$ serum. Cultures were set up in round bottom microtiter plates (Dynateck, Nürtingen, FRG) and contained $50 \mu$ l cell suspension, $50 \mu \mathrm{l}$ mitogen solution, and 50 $\mu$ l diluted tissue culture-conditioned medium. Cell cultures were incubated for 96 $\mathrm{hr}$ at $37^{\circ} \mathrm{C}$ in humidified air with $5 \% \mathrm{CO}_{2}$. Mitogen concentrations giving optimal stimulation were used: concanavalin A (Con A; 79-003, Miles, Slough, UK), 2 $\mu \mathrm{g} /$ culture and phytohemagglutinin (PHA; HA 15, Welcome, Beckenham, UK), 10 $\mu \mathrm{g} /$ culture. Sixteen hours before the end of the incubation period $1 \mu \mathrm{Ci}$ [methyl${ }^{3} \mathrm{H}$ ]thymidine ( $5 \mathrm{Ci} / \mathrm{mmol}$, Radiochemical Centre Amersham, UK) was added to each well. The cells were collected on Titertek glassfiber filters with an automatic culture harvester (Skatron, Lierbyen, Norway). The air-dried filters were placed 
in scintillation vials and $2.5 \mathrm{ml}$ toluene scintillator was added. Radioactivity was measured with a Nuclear Chicago liquid scintillation counter (NC 725). Results are expressed as the mean cpm of quadruplicate cultures \pm standard error (SE). Statistical analyses were performed by Student's $t$ test.

In order to investigate the effect of HTECM on mature T lymphocytes, peripheral blood lymphocytes (PBL) from normal donors were isolated from heparinized blood by Ficoll-Isopaque centrifugation at $1000 \mathrm{~g}$ for $20 \mathrm{~min}$ (12). Lymphocyte concentration was adjusted to $0.8 \times 10^{6} / \mathrm{ml}$ and the cells were cultured under the same conditions as described for thymocytes. Mitogen concentrations were: Con A, $2 \mu \mathrm{g} /$ culture and PHA, $6 \mu \mathrm{g} /$ culture.

Animals. Six- to eight-week-old female Swiss inbred mice were used throughout all these experiments. The animals were reared under conventional conditions with mouse pellets and tap water ad libitum.

Hydrocortisone treatment. Mice were injected intraperitoneally with a single dose of $2.5 \mathrm{mg}$ hydrocortisone acetate (HC) (Hydro-Adreson, Organon, Oss, NL) which results in rapid loss of corticosteroid-sensitive thymocytes $\left(T_{r s}\right)$ localized in the thymus cortex (13). This yields a small population of corticosteroid-resistant thymocytes $\left(\mathrm{T}_{\mathrm{cr}}\right)$ confined to the medulla which is supposed to contain the functional $\mathrm{T}$ lymphocytes normally present in the thymus. Thymuses were removed at various days after $\mathrm{HC}$ treatment and the cells isolated from the tissue were used in the stimulation assay described in the next section.

Mitogen stimulation of mouse lymphocytes. Animals were killed by cervical dislocation and thymus, spleen, and lymph nodes (axillary and inguinal) were dissected out under sterile conditions and minced in H-RPMI. Cell suspensions were adjusted to $4 \times 10^{6} / \mathrm{ml}$ in RPMI-1640 with bicarbonate, antibiotics, and $10 \%$ AB serum. Cultures were set up as described for human lymphocytes. Mitogens used were: Con A, $1 \mu \mathrm{g} /$ culture, PHA $10, \mu \mathrm{g} /$ culture, and lipopolysaccharide (LPS, E. coli 0127: B8; Difco, Detroit, Mich.), $10 \mu \mathrm{g} /$ culture. After 2 days $1 \mu \mathrm{Ci}$ $\left[{ }^{3} \mathrm{H}\right] \mathrm{TdR}$ was added and $7 \mathrm{hr}$ later the cultures were harvested and radioactivity was measured as described above.

\section{RESULTS}

\section{Thymic Epithelial Cultures}

During the first days of culture large rounded cells with some fibroblasts were seen around the explants. The lymphocytes released by the explants were almost completely removed after two medium changes. At Days 4-7 the rounded cells disappeared and outgrowth of polygonal cells was seen at the edge of the explants. These cells formed continuous sheets with fibroblasts at the periphery of the outgrowth. From Day 14 on Hassall's corpuscles could be seen at the outer part of the circular fields as described previously (14). Cultures fixed and embedded in situ in plastic flasks were examined with the electron microscope and showed desmosomes with tonofibrils, confirming their epithelial nature. Since the adherence of fibroblasts is much less than that of epithelial cells (15), selective trypsinization with $0.01 \%$ trypsin-EDTA solution was carried out in cultures with an excess of fibroblasts at Week 2 or 3 . However, fibroblasts could never be com- 
pletely removed and after 4-6 weeks fibroblasts had overgrown the epithelial cells.

\section{Control Cultures}

Fibroblasts grown from a cervical biopsy were subcultured 17 times, and conditioned media were used from subcultures 3 and later.

Explants of labial mucosae and salivary glands showed outgrowth of epithelial cells from Day 4, giving a monolayer after 2 to 3 weeks. These cultures were almost free of fibroblasts. After about 5 weeks the epithelial fields tended to lose contact with the culture flask.

\section{Effect of Conditioned Media on Con A and PHA Response of Human Thymocytes}

Human thymocytes cultured with mitogen and conditioned medium were examined for increased DNA synthesis as measured by $\left[{ }^{3} \mathrm{H}\right] \mathrm{TdR}$ incorporation. Cultures with HTECM gave a significantly higher $(P<0.025)$ Con A and PHA response as compared with control conditioned media in dilutions up to 1:90 (Fig. 1). The $\left[{ }^{3} \mathrm{H}\right] \mathrm{TdR}$ incorporation of thymocytes cultured with HTECM at a dilution of 1:30 was increased by factor $1.8 \pm 0.3$ (mean $\pm \mathrm{SD}, n=10$ ) for Con A and $2.2 \pm$ $0.6(n=9)$ for PHA. Different batches of HTECM showed slight differences in their activities. HTECM collected from cultures of limited diameter (Day 10) was less active than that collected at later times when the outgrowth of the same cultures had extended over large parts of the culture flask. Conditioned media of cultures older than 4 weeks became usually less active. We found a maximum increase of PHA response when HTECM was diluted to 1:30 and the highest Con A response with dilutions between 1:6 and 1:18.

As can be seen in Fig. 1 control conditioned medium from labial mucosa epithelium showed no increase in $\left[{ }^{3} \mathrm{H}\right] \mathrm{TdR}$ incorporation; in high concentrations it was even inhibitory to the Con A response. $\left[{ }^{3} \mathrm{H}\right] \mathrm{TdR}$ incorporation of unstimulated cultures was slightly increased by HTECM but not by control conditioned medium. The same results were obtained using the other control conditioned media from fibroblasts, HeLa cells, and salivary gland epithelium.

Since the presence of thymocytes in the epithelial cultures could not be completely excluded, conditioned medium from cultured thymocytes was used as another control. This had no effect on mitogen responsiveness of thymocytes.

\section{Effect of Conditioned Media on Con A and PHA Response of Human PBL}

HTECM and control conditioned media added in different dilutions to human PBL stimulated with optimal doses Con A and PHA showed no increase of the mitogen response (Table 1).

\section{Effect of Conditioned Media on Mitogen Response of Mouse Thymocytes}

Mouse thymocytes cultured with mitogen and HTECM gave higher $\left[{ }^{3} \mathrm{H}\right] \mathrm{TdR}$ incorporation than mitogen-stimulated cultures to which control conditioned medium was added (Fig. 2). The $\left[{ }^{3} \mathrm{H}\right] \mathrm{TdR}$ incorporation of thymocytes cultured with HTECM at a dilution of 1:30 was increased by factor $2.6 \pm 0.6$ (mean $\pm \mathrm{SD}, n$ $=13)$ for Con $\mathrm{A}$ and $5.8 \pm 1.5(n=13)$ for PHA. Also a slight increase was measured when control conditioned media were added, but the increase in mitogen responsiveness of thymocytes cultured with HTECM was significantly higher 


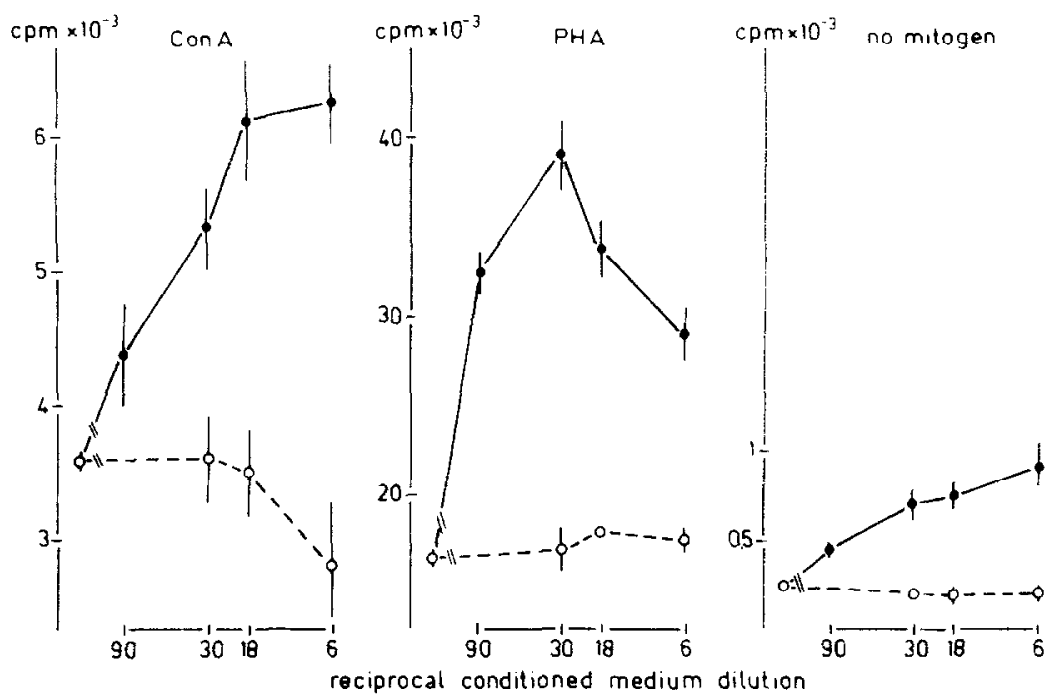

FIG. 1. $\left[{ }^{3} \mathrm{H}\right] \mathrm{TdR}$ incorporation into mitogen-stimulated and-unstimulated human thymocytes cultured with various dilutions of HTECM (-) or HLECM (--). Mitogen doses giving optimal stimulation were used.

than that of cultures with control conditioned media even at dilutions up to 1:90 $(P$ $<0.0025$ ). This effect of increase in DNA synthesis caused by nonthymic culture conditioned media was seen only in cultures with mouse thymocytes but not with human thymocytes. Unstimulated mouse thymocytes cultured with HTECM gave higher $\left[{ }^{3} \mathrm{H}\right] \mathrm{TdR}$ incorporation than those cultured with control conditioned media.

Effect of Conditioned Media on Mitogen Response of Mouse Lymphocytes from

Spleen and Lymph Nodes

To study the effect of HTECM on more mature T lymphocytes, mouse spleen and lymph node cells were stimulated with Con A and PHA and tissue culture conditioned media were added. Table 2 gives a summary of experiments in which the effect of HTECM was tested simultaneously on thymus, spleen, and lymph node cells. The mitogen response of lymph node cells and the Con A response of

TABLE 1

Effect of Conditioned Media on T Mitogen Response of Human PBL

\begin{tabular}{|c|c|c|c|c|}
\hline $\begin{array}{l}\text { Conditioned } \\
\text { medium }\end{array}$ & $\begin{array}{l}\text { Final } \\
\text { dilution }\end{array}$ & Con A & PHA & No mitogen \\
\hline HTECM & $1 / 6$ & $25,316 \pm 1241^{a}$ & $57,082 \pm 2151$ & $1481 \pm 152$ \\
\hline HTECM & $1 / 30$ & $22,228 \pm 505$ & $55,088 \pm 1705$ & $732 \pm 200$ \\
\hline HFCM & $1 / 6$ & $26,657 \pm 1094$ & $36,950 \pm 2528$ & $622 \pm 133$ \\
\hline $\mathrm{HFCM}^{b}$ & $1 / 30$ & $19,218 \pm 1130$ & $48,092 \pm 2979$ & $644 \pm 154$ \\
\hline RPMI & & $24,456 \pm 320$ & $62,823 \pm 3011$ & $722 \pm 169$ \\
\hline
\end{tabular}

\footnotetext{
${ }^{a}$ Mean cpm of $\left[{ }^{3} \mathrm{H}\right] \mathrm{TdR}$ incorporation of quadruplicate cultures $\pm \mathrm{SE}$ of a representative experiment out of four.

${ }^{b}$ Other control conditioned media gave the same results.
} 


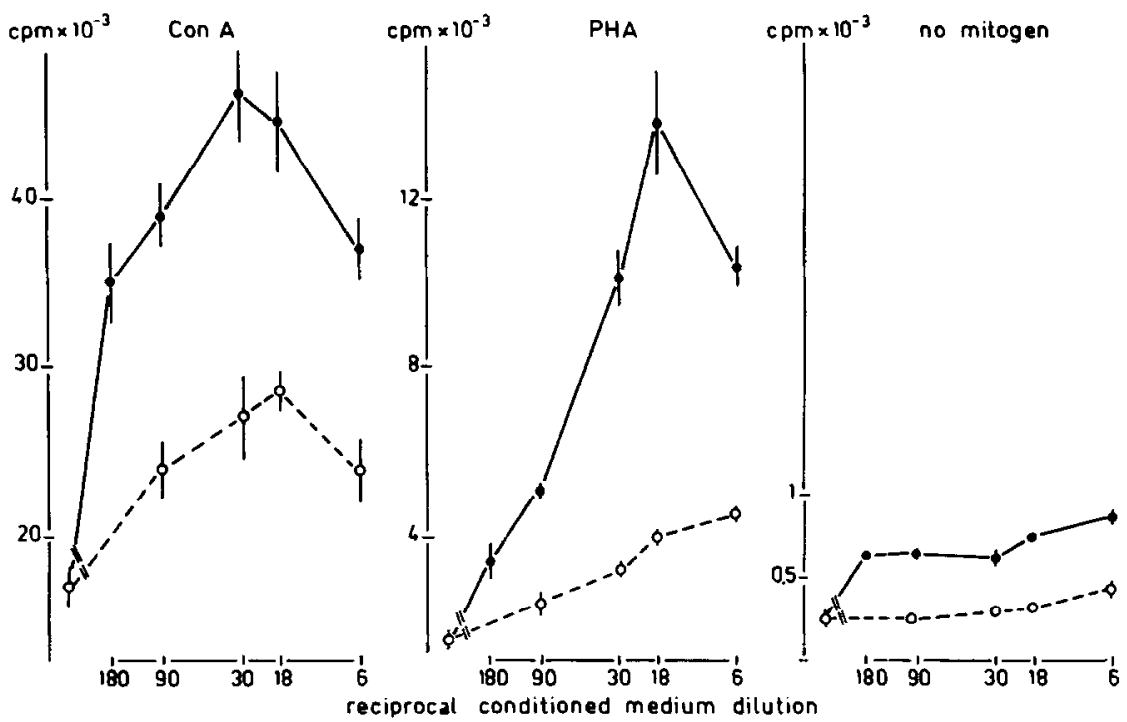

FIG. 2. $\left[{ }^{3} \mathrm{H}\right] \mathrm{TdR}$ incorporation into mitogen-stimulated and -unstimulated mouse thymocytes cultured with various dilutions of HTECM (-) or HLECM (---).

spleen cells were not affected by HTECM. The PHA response of spleen cells was found to be increased by HTECM at a dilution of 1:30. This could mean that thymus and spleen contain an identical population of target cells for HTECM. Therefore, we compared the PHA response of thymocytes and spleen cells cultured with several dilutions of HTECM (Fig. 3). The two curves appeared to be quite similar, but the net increase in PHA response of thymocytes was smaller than that of spleen cells.

TABLE 2

Effect of Conditioned Media on Mitogen Response of Mouse Lymphocytes

\begin{tabular}{|c|c|c|c|c|c|}
\hline \multirow{2}{*}{$\begin{array}{l}\text { Conditioned } \\
\text { medium }\end{array}$} & \multirow{2}{*}{$\begin{array}{c}\text { Final } \\
\text { dilution }\end{array}$} & \multirow[b]{2}{*}{ Mitogen } & \multicolumn{3}{|c|}{ Lymphocyte source } \\
\hline & & & Thymus & Spleen & Lymph nodes \\
\hline HTECM & $1 / 30$ & Con $A$ & $37,442 \pm 872^{n}$ & $194,257 \pm 6,818^{h}$ & $76,514 \pm 4,060$ \\
\hline HLECM $^{c}$ & $1 / 30$ & & $18,062 \pm 633$ & $195,488 \pm 5,012$ & $81,939 \pm 143$ \\
\hline HTECM & $1 / 30$ & PHA & $12,864 \pm 1145^{a}$ & $195,705 \pm 6,179^{d}$ & $89,723 \pm 3,630$ \\
\hline $\mathrm{HLECM}^{c}$ & $1 / 30$ & & $3,176 \pm 123$ & $157,508 \pm 5,743$ & $93,654 \pm 1,653$ \\
\hline HTECM & $1 / 30$ & LPS & $857 \pm 79$ & $55,208 \pm 1,218$ & $2,330 \pm 260$ \\
\hline HLECM $^{c}$ & $1 / 30$ & & $829 \pm 158$ & $61,446 \pm 1,989$ & $2,127 \pm 252$ \\
\hline HTECM & $1 / 30$ & No & $366 \pm 84$ & $1,054 \pm 186$ & $671 \pm 101$ \\
\hline HLECM & $1 / 30$ & mitogen & $215 \pm 50$ & $743 \pm 92$ & $528 \pm 187$ \\
\hline
\end{tabular}

${ }^{a} P<0.0005$.

${ }^{b}$ Mean cpm of $\left[{ }^{3} \mathrm{H}\right] \mathrm{TdR}$ incorporation of quadruplicate culturcs $\pm \mathrm{SE}$ of a representative experiment out of three.

${ }^{c}$ With other control conditioned media the same results were obtained.

d $P<0.0025$. 


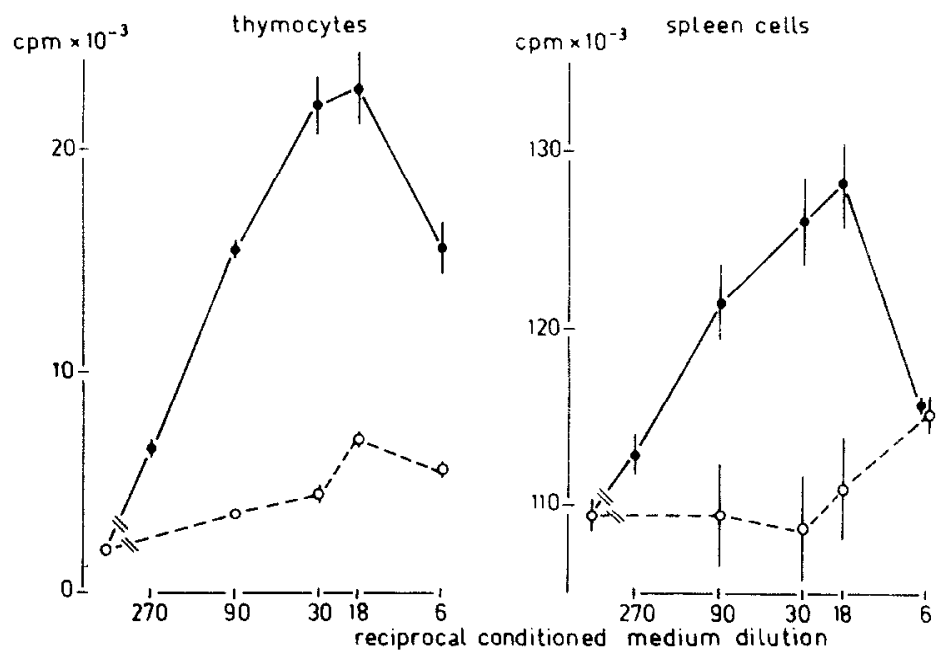

FIG. 3. $\left[{ }^{3} \mathrm{H}\right] \mathrm{TdR}$ incorporation into PHA-stimulated mouse thymocytes and spleen cells cultured with various dilutions of HTECM $(-)$ or HLECM (---).

Because of the fact that LPS is considered to be a specific B-cell mitogen in mice (16) we also used LPS to study the effect of HTECM on the B-mitogen response of mouse lymphocytes. LPS and tissue culture-conditioned media were added to thymocytes, spleen, and lymph node cells. LPS stimulation of thymocytes was extremely low, but spleen and lymph node cells could be stimulated with LPS (Table 2). No effect of HTECM or other conditioned media was found on the response of mouse lymphocytes to LPS.

\section{Target Cell for HTECM in Mouse Thymic Lymphocyte Population}

In order to evaluate which thymocyte population is affected by HTECM, mice were injected with HC. Three days after treatment the number of thymocytes declined to 5-10\% of the cell number of a normal thymus, while repopulation of the thymus was noted from the seventh day after $\mathrm{HC}$ treatment. The effect of HTECM on mitogen responsiveness of thymocytes from mice at various days after $\mathrm{HC}$ treatment was studied to investigate its effect on cortisone resistant thymocytes ( $\mathrm{T}_{\mathrm{cr}}$, Day 3 after $\mathrm{HC}$ ) and on immature lymphocytes entering the thymus during the repopulation period. As shown in Figs. $4 a$ and $b$ there was a relative increase in reactivity to both Con $\mathrm{A}$ and PHA in the first 5 days after HC treatment when the total thymic cell number diminished. During the subsequent regeneration of the thymus the reactivity to both mitogens decreased and reached a minimum below control values around Day 12. As can be noted in Fig. 4a the effect of HTECM on $\left[{ }^{3} \mathrm{H}\right] \mathrm{TdR}$ incorporation in Con A-stimulated thymocytes was absent at Days 3-5, reached normal levels at Day 7, and was absent again around Day 12. The increase in $\left[{ }^{3} \mathrm{H}\right] \mathrm{TdR}$ incorporation in PHA-stimulated thymocytes caused by HTECM was maximal at Days 3-5 and dropped to zero around Day 12 (Fig. 4b). The mitogen reactivity of thymocytes and the effect of HTECM reached normal levels at Day 24. 

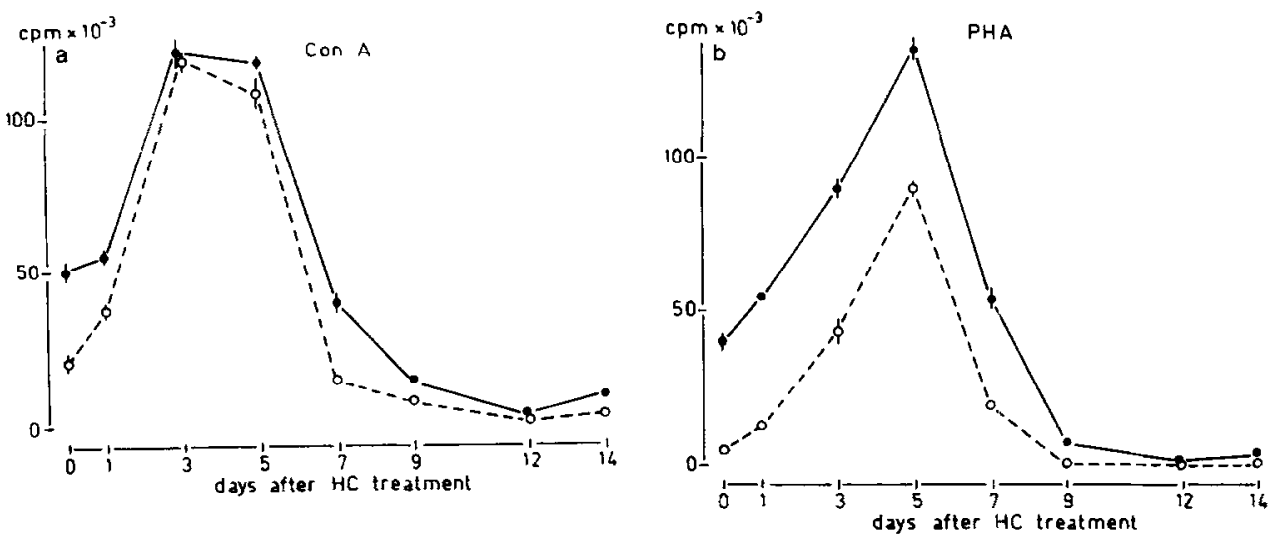

FIG. 4. $\left[{ }^{3} \mathrm{H}\right] \mathrm{TdR}$ incorporation into Con A- (a) or PHA- (b) stimulated mouse thymocytes, obtained from mice various days after HC treatment, cultured with HTECM at a dilution of 1:30 ( $\longrightarrow$ ) or without conditioned medium (---). Each point is the mean \pm SE of three different experiments. Bars are omitted if they are smaller than the figures.

To get a better understanding of the effect of HTECM on the mitogen response of the different thymocyte subpopulations, mixtures of thymocytes 3 days $\left(T_{c r}\right)$ and 12 days $\left(T_{12}\right)$ after $H C$ were used (Figs. 5a and b). Con A and PHA response increased with increasing numbers of $T_{\mathrm{cr}}$. The effect of HTECM on the Con A response was already seen with $5 \% \mathrm{~T}_{\mathrm{rr}}$ and reached its maximum with $20 \% \mathrm{~T}_{\mathrm{cr}}$; no effect was seen with either $100 \% \mathrm{~T}_{\mathrm{cr}}$ or $100 \% \mathrm{~T}_{12}$. The effect of HTECM on the PHA response increased with rising numbers of $T_{\mathrm{rr}}$ and was maximal with $100 \%$ $\mathrm{T}_{\mathrm{cr}}$.

\section{DISCUSSION}

Several thymic humoral factors are described inducing T-lymphocyte matura-
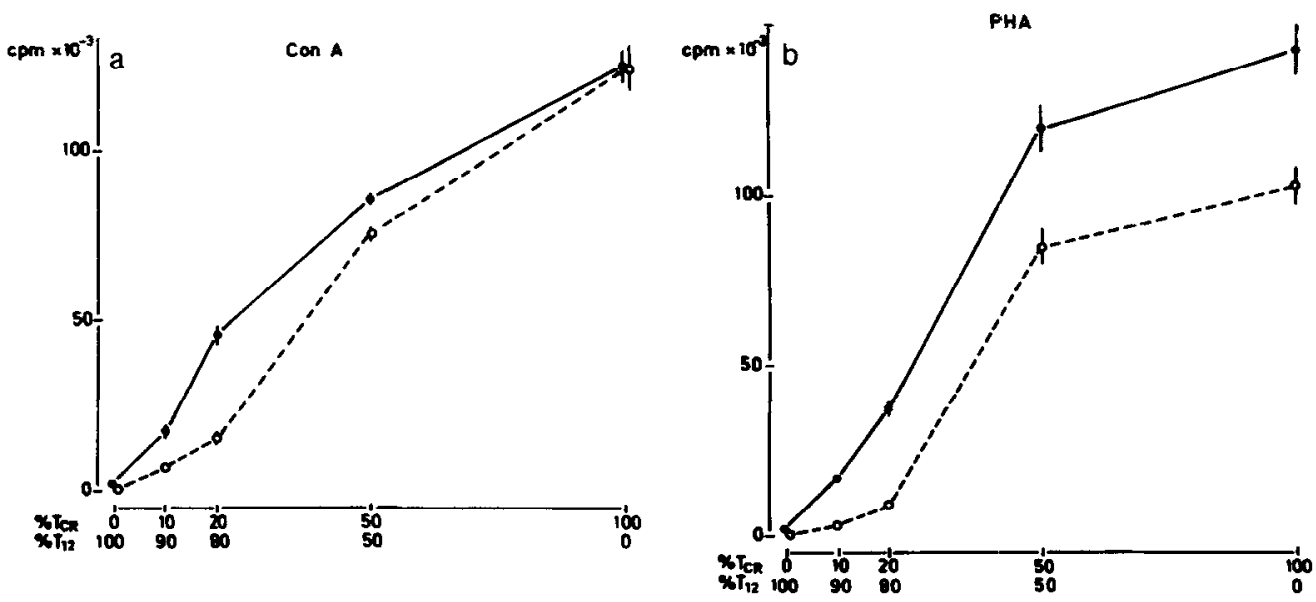

FIG. 5. The dotted line represents the $\left[{ }^{3} \mathrm{H}\right] \mathrm{TdR}$ incorporation into mixtures of $\mathrm{T}_{\mathrm{er}}$ and $\mathrm{T}_{\mathrm{k} z}$ stimulated with Con A (a) or PHA (b). The solid line shows the $\left[{ }^{3} \mathrm{H}\right]$ TdR incorporation when HTECM at a dilution of 1:30 was added. $T_{c r}$, thymocytes obtained 3 days after HC treatment: $T_{12}$, thymocytes obtained 12 days after $\mathrm{HC}$ treatment. Each point is the mean $\pm S E$ of three different experiments. 
tion. Most of these are whole thymic extracts, which makes it difficult to discriminate between epithelial and lymphocytic factors. Thymic epithelial cultures can be used to get around this difficulty. We have studied the effects of human thymic epithelial-conditioned medium on mitogen response of human and mouse lymphocytes. Although HTECM most probably represents a mixture of both stimulating and depressing factors, our results show that HTECM increases the responsiveness of human thymocytes to Con A and PHA (as measured by $\left[{ }^{3} \mathrm{H}\right] \mathrm{TdR}$ incorporation) while other conditioned media, from fibroblast as well as epithelial origin, fail to do so. Others (17) found an effect only on the Con A but not the PHA response of human thymocytes. HTECM also elevates the Con A and PHA response of mouse thymocytes. This latter observation indicates that the activity expressed by HTECM is not species specific. Evidence for the thymic epithelial origin of the factor in HTECM stems from the following observations:

(a) Even though human thymic epithelial cultures are always contaminated with fibroblasts, conditioned media from pure fibroblast cultures do not increase the mitogen response.

(b) Conditioned media from HeLa cells and epithelial cultures other than thymus, i.e., sublabial mucosa and salivary gland, give results similar to those from fibroblast cultures. Conditioned media from nonthymic cultures have no effect on mitogen response of human thymocytes but always cause a small increase in mitogen response of mouse thymocytes. This phenomenon may be due to the difference in species, possibly caused by cell surface antigens shed into the medium. No effect of HTECM on mitogen stimulation of human PBL is seen. This suggests that the target cell for HTECM is a rather immature human T lymphocyte.

The PHA but not the Con A and LPS responsc of mouse spleen cells is increased by HTECM. The mitogen response of mouse lymph node cells is not affected by HTECM. From these data the conclusion can be drawn that the thymus and, to a lesser extent, the spleen, contain a cell population (apparently not B lymphocytes) which is sensitive to HTECM. Spleen cells of mice have been shown to contain target cells for thymic humoral factors but effects on mitogen response are seen only after preincubation (18) or after separation of spleen cells on discontinuous BSA gradients $(19,20)$. This enrichment of target cells in the spleen is not needed to demonstrate the effect of HTECM.

Three days after $\mathrm{HC}$ treatment of mice the thymus is deprived of cortical thymocytes and contains mainly medullary thymocytes (13). Using Con A stimulation we have been unable to demonstrate any effect of HTECM on $T_{\mathrm{cr}}$ (Fig. 4). This implies that the effect of HTECM on the Con A response of total thymocytes has to be attributed to an effect on $\mathrm{T}_{\mathrm{cs}}$. With PHA stimulation, however, the effect of HTECM increases with the relative increase of $T_{c r}$ between Day 1 and Day 5 after $\mathrm{HC}$ treatment, indicating that there is nevertheless an effect of HTECM on the more mature $T_{c r}$. These effects are about the same as those found on spleen cells. These observations can be explained by assuming that the Con A response of $\mathrm{T}_{\mathrm{cr}}$ and spleen cells is already maximal. However, the response of both cell populations to PHA is lower than that of peripheral T lymphocytes (4) and apparently HTECM can increase this responsiveness.

Twelve days after $\mathrm{HC}$ treatment the thymus contains lymphocytes $\left(T_{12}\right)$ that do 
not respond to Con A and PHA; HTECM cannot induce this responsiveness. This may be due to the disappearance of $T_{\mathrm{cr}}$ from the thymus. Data of Dumont (21) about the electrophoretic mobility of thymocytes after $\mathrm{HC}$ treatment support this idea.

Addition of increasing numbers of $\mathrm{T}_{\mathrm{cr}}$ to $\mathrm{T}_{12}$, keeping the total cell number constant, results in increased response to Con A and PHA. The effect of HTECM on the PHA response is maximal with $100 \% \mathrm{~T}_{\mathrm{er}}$, confirming the results shown in Fig. 4b. To induce Con A reactivity in $T_{12}$, Con A-stimulated $T_{c r}$ or lymph node cells are needed $(13,22)$. A stimulating effect of HTECM on the Con A response of these mixtures is seen with $5 \% \mathrm{~T}_{\mathrm{cr}}$ and the effect is maximal with $20 \% \mathrm{~T}_{\mathrm{cr}}$ (Fig. $5 a)$. The same holds true when lymph node cells instead of $T_{\mathrm{cr}}$ are added, indicating that HTECM has an effect on the Con A response of $T_{12}$ but this can be seen only in the presence of Con A-stimulated mature $T$ lymphocytes.

Our findings that HTECM affect both mouse thymocytes subpopulations seem to be in conflict with data concerning rat thymocytes (9). In that study effects of rat thymic epithelial culture supernatants are seen only on T-mitogen response of rat $\mathrm{T}_{\mathrm{cs}}$.

The relationship between HTECM and thymic humoral factors obtained from thymus extracts remains unclear. It has been found that mouse thymocytes or spleen cells preincubated with thymic humoral factor (THF) exhibit higher Con A and PHA responses (23). But THF directly added to the mitogen-stimulated spleen cell cultures gives an inhibition; no data are shown for thymocytes. Thymosin fraction 5 is known to increase the capacity of mouse thymocytes to react in a one-way mixed lymphocyte culture when added to the culture (24). We tested the effect of thymosin fraction 5 and mixtures of HTECM and thymosin on T-mitogen response of different lymphoid cell populations. We never found any increasing effect of thymosin in doses ranging from 0.1 to $100 \mu \mathrm{g} / \mathrm{ml}$. With high concentrations of thymosin up to $100 \mu \mathrm{g} / \mathrm{ml}$ a $50 \%$ inhibition of the Con A response was seen (unpublished observations).

This study indicates that HTECM in vitro acts on T lymphocytes in different stages of development.

\section{ACKNOWLEDGMENTS}

The authors would like to express their appreciation to the cardiac surgery teams of the University Children's Hospital Het Wilhelmina Kinderziekenhuis and the Antonius Hospital in Utrecht for their attention in providing us with thymus tissue. Thymosin fraction 5 (lot BPM 390) was kindly provided by Dr. A. L. Goldstein. The electron microscopy studies were performed by Dr. L. Rademakers. The help of Dr. R. E. Ballieux in preparing the manuscript is gratefully acknowledged.

\section{REFERENCES}

1. Good, R. A., In "Clinical Immunobiology" (J. F. Bach and R. A. Good, Eds), Vol. 1, p. 1. Academic Press, New York, 1972.

2. Stutman, O., and Good, R. A., In "Contemporary Topics in Immunobiology" (A. J. S. Davies and R. L. Carter, Eds), Vol. 2, p. 299. Plenum Press, New York, 1973.

3. Owen, J. J. T., and Ritter, M. A., J. Exp. Med. 129, 431, 1969

4. Dyminski, J. W., and Smith, R. T., Ser. Haemat. 7, 524, 1974.

5. van Bekkum, D. W. (Ed.), "The Biological Activity of Thymic Hormones." Kooyker Scientific Publications, Rotterdam, 1975.

6. Bach, J. F., and Carnaud, C., Prog. Allergy 21, 342, 1976.

7. Pyke, K. W., and Gelfand, E. W.. Nature (London) 251, 421, 1974. 
8. Papiernik, M., Nabarra, B., and Bach, J. F., Clin. Exp. Immunol. 19, 281, 1975.

9. Kruisbeek, A. M., Kröse, T. C. J. M., and Zijlstra, J. J., Eur. J. Immunol. 7, 375, 1977.

10. Kruisbeek, A. M., Astaldi, G. C. B., Blankwater, M. J., Zijlstra, J. J., Levert, L. A. . and Astaldi, A., Cell. Immunol. 35, 134, 1978.

11. Hamilton. W. J., Boyd, J. O., and Mossman, H. W., "Human Embryology: Prenatal Development of Form and Function," p. 162. Heffer, Cambridge, 1972.

12. Bøyum. A., Scand. J. Clin. Lab. Invest. Suppl. 21, 97, 1968.

13. Jacobsson, H., and Blomgren, H., Cell. Immunol. 11, 427, 1974.

14. Kater, L. In "Contemporary Topics in Immunobiology" ( A. J. S. Davies and R. L. Carter, Eds.). Vol. 2, p. 101. Plenum Press, New York, 1973.

15. Owens, R. B., Smith. H. S., Nelson-Rees. W. A.. and Springer. E. L.. J. Nat. Cancer Inst. 56, 843, 1976.

16. Andersson, J., Möller, G., and Sjöberg, O., Cell. Immunol. 4. 381, 1972.

17. Hensen. E. J., Hoefsmit, E. C. M., and Van den Tweel, J. G., Clin. Exp. Immunol. 32, 309, 1978.

18. Rotter, V., and Trainin, N., Cell. Immunol. 16, 413, 1975.

19. Komuro, K., and Boyse, E. A., J. Exp. Med. 138, 479, 1973.

20. Basch, R. S., and Goldstein, G., Cell. Immunol. 20, $218,1975$.

21. Dumont. F.. Immunology 34, 841, 1978.

22. Paetkau, V., Mills, G., Gerhart, S., and Monticone, V., J. Immunol. $1171320,1976$.

23. Rotter, V., and Trainin, N., Isr. J. Med. Sci. 13, 363, 1977.

24. Cohen, G. H., Hooper, J. A., and Goldstein, A. L., Ann. N.Y. Acad. Sci. 249, 145, 1976. 